\title{
Porcine dentin sialoprotein glycosylation and glycosaminoglycan attachments
}

Yasuo Yamakoshi', Takatoshi Nagano², Jan CC Hu' ${ }^{1}$, Fumiko Yamakoshi ${ }^{1}$, James P Simmer ${ }^{1 *}$

\begin{abstract}
Background: Dentin sialophosphoprotein (Dspp) is a multidomain, secreted protein that is critical for the formation of tooth dentin. Mutations in DSPP cause inherited dentin defects categorized as dentin dysplasia type II and dentinogenesis imperfecta type II and type III. Dentin sialoprotein (Dsp), the N-terminal domain of dentin sialophosphoprotein (Dspp), is a highly glycosylated proteoglycan, but little is known about the number, character, and attachment sites of its carbohydrate moieties.

Results: To identify its carbohydrate attachment sites we isolated Dsp from developing porcine molars and digested it with endoproteinase Glu-C or pronase, fractionated the digestion products, identified fractions containing glycosylated peptides using a phenol sulfuric acid assay, and characterized the glycopeptides by $\mathrm{N}$-terminal sequencing, amino acid analyses, or LC/MSMS. To determine the average number of sialic acid attachments per N-glycosylation, we digested Dsp with glycopeptidase A, labeled the released N-glycosylations with 2-aminobenzoic acid, and quantified the moles of released glycosylations by comparison to labeled standards of known concentration. Sialic acid was released by sialidase digestion and quantified by measuring $\beta$-NADH reduction of pyruvic acid, which was generated stoichiometrically from sialic acid by aldolase. To determine its forms, sialic acid released by sialidase digestion was labeled with 1,2-diamino-4,5-methyleneoxybenzene (DMB) and compared to a DMB-labeled sialic acid reference panel by RP-HPLC. To determine the composition of Dsp glycosaminoglycan (GAG) attachments, we digested Dsp with chondroitinase ABC and compared the chromotagraphic profiles of the released disaccharides to commercial standards. N-glycosylations were identified at $\mathrm{Asn}^{37}, \mathrm{Asn}^{77}, \mathrm{Asn}^{136}, \mathrm{Asn}^{155}, \mathrm{Asn}{ }^{161}$, and Asn ${ }^{176}$. Dsp averages one sialic acid per N-glycosylation, which is always in the form of $\mathrm{N}$-acetylneuraminic acid. O-glycosylations were tentatively assigned $\mathrm{at} \mathrm{Thr}^{200}$, $\mathrm{Thr}^{216}$ and $\mathrm{Thr}^{316}$. Porcine Dsp GAG attachments were found at $\operatorname{Ser}^{238}$ and $\operatorname{Ser}^{250}$ and were comprised of chondroitin 6-sulfate and chondroitin 4-sulfate in a ratio of 7 to 3 , respectively.

Conclusions: The distribution of porcine Dsp posttranslational modifications indicate that porcine Dsp has an $\mathrm{N}$-terminal domain with at least six N-glycosylations and a C-terminal domain with two GAG attachments and at least two O-glycosylations.
\end{abstract}

\section{Background}

Type I collagen and proteolytic cleavage products of dentin sialophosphoprotein (Dspp) are the predominant proteins in tooth dentin. Collagen constitutes about $90 \%$ of the dentin organic matrix [1], while Dspp-derived proteins make up more than half of the dentin noncollagenous proteins [2-5]. Genetic studies have demonstrated the importance of the genes encoding type I

\footnotetext{
* Correspondence: jsimmer@umich.edu

'Department of Biologic and Materials Sciences, University of Michigan School of Dentistry, 1210 Eisenhower Place, Ann Arbor, MI, 48108, USA Full list of author information is available at the end of the article
}

collagen (COL1A1, 17q21.31-q22; COL1A2, 7q22.1) and $D S P P(4 \mathrm{q} 21.3)$ for proper human dentin formation. Inherited dentin defects are classified as dentinogenesis imperfecta (DGI) types I, II, or III, or dentin dysplasia (DD) types I and II [6]. DGI type I is osteogenesis imperfecta with dentinogenesis imperfecta and is caused by mutations in COL1A1 and COL1A2 [7]. DD type II and DGI types II and type III are caused by mutations in DSPP [8-24]. There are other potential candidate genes for these disorders, but only DSPP mutations have been found in DD or DGI kindreds [25].
C Biomed Central

(ㄷ) 2011 Yamakoshi et al; licensee BioMed Central Ltd. This is an Open Access article distributed under the terms of the Creative Commons Attribution License (http://creativecommons.org/licenses/by/2.0), which permits unrestricted use, distribution, and reproduction in any medium, provided the original work is properly cited. 
Dentin sialophosphoprotein (Dspp) is a chimeric protein that is cleaved by proteases into its component parts [26], which are considered to be two parts in rodents and three in pig. The order of the major domains of Dspp is Dsp-Dgp-Dpp, where Dsp is dentin sialoprotein, Dgp is dentin glycoprotein, and Dpp is dentin phosphoprotein. Dspp is expressed predominantly by odontoblasts [27], but is detected in bone at trace levels ( $0.25 \%$ of the level in dentin) [28]. Currently, the human expressed sequence tag database for DSPP expression (Hs.678914) shows zero DSPP transcripts out of 71,655 total mRNA transcripts characterized from bone.

Dspp is a member of the secretory calcium-binding phosphoprotein (SCPP) genes, which are involved in the mineralization of bone, dentin, and enamel [29]. The SCPP family initially arose from a single ancestral gene: SPARCL1 or secreted protein, acidic, cysteine-rich like 1 gene [30]. The common features of SCPP genes are few: their second exon encodes a short signal peptide $(\sim 15$ amino acids in length) plus the first two amino acids of the secreted protein. The second coding exon generally encodes a phosphorylation site SXE/S(p) for Golgi casein kinase [30,31]. All of the introns are type 0 , that is, the introns do not interrupt codons but are all placed between codon triplets. The SCPPs divide into two groups based upon their distinctive amino acid compositions. Acidic SCPPs are rich (over 25\%) in glutamate, aspartate, and phosphoserine. Proline and glutaminerich SCPPs are more than 20\% proline and glutamine. Dspp belongs to the acidic group, which is also known as the dentin/bone group or the SIBLINGs, for small integrin-binding ligand, N-linked glycoproteins [32,33].

The second coding exon for Dspp (exon 3) is unusual for the SCPP family. In the pig, this exon encodes the protein segment from $\mathrm{Val}^{3}$ to $\mathrm{Gln}^{31}$. None of the amino acids encoded by exon 3 are in the appropriate context for phosphorylation or glycosylation. Skipping exon 3 would not alter the reading frame, but human mutations that cause the skipping of exon 3 cause dominant negative effects that result in dentin malformations, possibly due to failure to recognize or cleave the signal peptide [20]. All six of the reported intronic mutations in DSPP that cause inherited dentin defects are at the end of intron $2[9,20,24]$ or beginning of intron $3[12,14,17,18]$. Perhaps exon 3 was acquired by exon capture after the Dspp ancestral gene duplicated from another SCPP gene and is not descended from the short prototypical second coding exon that encodes a serine that gets phosphorylated.

Exon 4 encodes the bulk of dentin sialoprotein (Dsp), from $\mathrm{Asp}^{32}$ to $\mathrm{Lys}^{368}$ [34]. Previously we isolated and characterized a porcine "Dsp only" transcript. This mRNA transcript terminated at a polyadenylation/ cleavage site in intron 4 [35]. The porcine Dsp cleavage product ( $\mathrm{Ile}^{1}$ to $\mathrm{Arg}^{376}$ ) of Dspp is a highly glycosylated proteoglycan that forms covalent dimers [36]. The Dgp cleavage product ( $\mathrm{Ser}^{377}$ to Gly ${ }^{457}$ ) of Dspp is encoded by the 5' part of exon 5. Dgp, which has so far only been described in pig, has a single glycosylation $\left(\mathrm{Asn}^{382}\right)$ and four phosphoserines (Ser ${ }^{438}, \mathrm{Ser}^{440}, \mathrm{Ser}^{442}, \mathrm{Ser}^{447}$ ) that are in a highly conserved region near its carboxylterminus [37]. Dentin phosphoprotein (Dpp) is the highly phosphorylated carboxyl-terminal domain of Dspp, and is encoded by the rest of exon 5 . The coding region of Dpp varies in length among different individuals without affecting function [20,38]. Astacin proteases, such as Bmp-1 cleave Dpp from Dspp [39-41], while Mmp-20 separates Dsp and Dgp [42].

Dentin sialoprotein (Dsp) was previously thought to be only a minor component of dentin, perhaps only $10 \%$ as abundant as dentin phosphoprotein (Dpp) $[43,44]$, and later thought to be a nonfunctional pro-domain that was removed by proteases to activate Dpp [45]. Recently, however it has been determined that Dsp and Dpp are expressed in stoichiometric amounts as the $\mathrm{N}$-terminal and C-terminal domains of Dspp [26] and are found in equal molar amounts in dentin $[38,46]$. $D s p p$ null mice show severe dentin malformations that resemble those observed in human DGI-III [47]. Transgenic expression of the Dsp domain in the Dspp null background partially, but substantially, restores the dentin phenotype [48]. The widening of predentin observed in the Dspp knockout as well as the reduced volume of mineralized dentin are recovered, indicating that both Dsp and Dpp are necessary for normal dentin mineralization. The mechanisms through which Dsp contributes to dentin formation are unknown. Characterization of its posttranslational modifications (PTMs) is an important step in understanding its function.

\section{Results}

\section{Characterization of Dsp carbohydrate attachment sites}

We previously showed that porcine Dsp is a proteoglycan [36] and that porcine dentin extracts contain the intact Dsp (the N-terminal domain of Dspp), as well as lower molecular weight (LMW) cleavage products of Dsp [42]. It was also known that Dsp has glycosylations rich in sialic acid [34] and that porcine Dsp has eight potential N-glycosylation sites based upon analysis of its primary amino acid sequence [35]. To identify attachment sites and to better characterize the glycosaminoglycan (GAG) and other carbohydrate attachments in porcine Dsp, we first targeted the small glycosylated Dsp cleavage products (LMW-Dsp) from the N-terminal region of Dsp. As none of the dentin extracts are perfectly homogeneous with respect to their contents, we refer to each extract that we characterized using a 
notation that reflects the extraction and fractionation steps that produced it (see methods). Routine characterizations of these fractions (SDS-PAGE and Western blots) are provided in additional files online.

Demineralized dentin powder was subjected to a series of extraction procedures. A flow chart of the extractions is provided in Figure 1. Simple analyses of the extracts (SDS-PAGE stained with CBB and stains-all and a Dsp immunoblot) are shown in Additional file 1. Intact Dsp proteoglycan and its cleavage products containing GAG attachments segregated in the acid/ $\mathrm{NaCl}$ or "AN" extract, which was further fractionated by size exclusion chromatography. Dsp degradation products containing the GAG attachments displayed a stains-all positive smear migrating between 50 - to $100-\mathrm{kDa}$ on SDSPAGE, which were collected in the third (ANS1/2-R3) of five RP-HPLC fractions (Additional file 2). ANS1/2$\mathrm{R} 3$ was resolved into two final fractions by repeating the RP-HPLC run. These two fractions (ANS1/2-R3a and ANS1/2-R3b) were digested with chondroitinase $A B C$ to degrade their GAG attachments, which converted the proteoglycan smears on SDS-PAGE into small peptides (Figure 2A) that contained no disulfide bridges, as their mobilities were not affected by the presence or absence of $\beta$-mercaptoethanol (Figure 2B). Chondroitinase ABC digestion converted ANS1/2-R3a into four peptides and

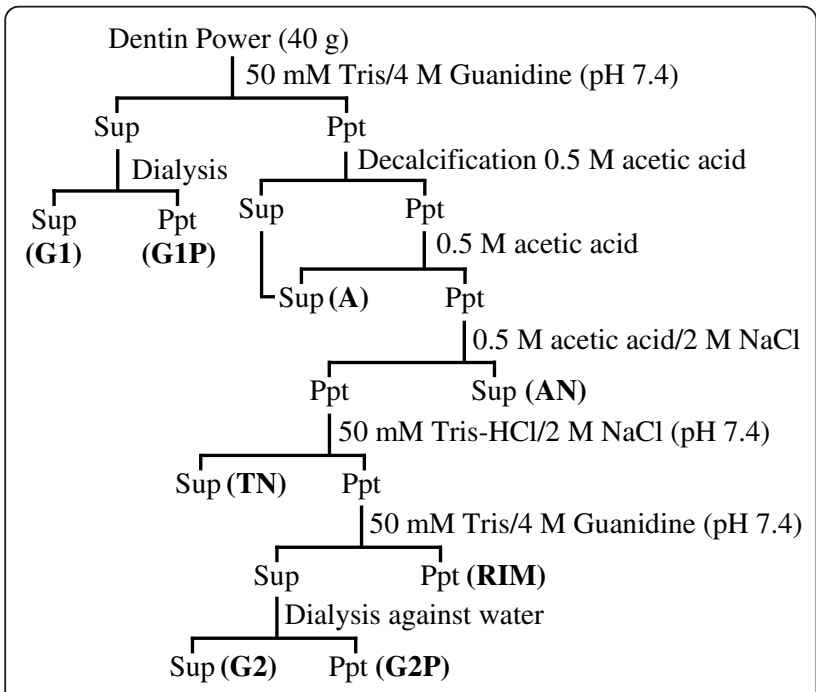

Figure 1 Dentin power extraction diagram. The extracts, in bold, are the first guanidine extract (G1), first guanidine pellet (GIP), acid (A), acid salt (AN), Tris salt (TN), residual insoluble material (RIM), second guanidine extract (G2), and the second guanidine pellet (G2P). Selected extractions were fractionated to isolate Dspp cleavage products. The AN extract was fractionated by size exclusion (S) and RP-HPLC (R) to yield HMW Dsp in fractions ANS1/ 2-R3, ANS1/2-R4, and ANS1/2-R5. The A extract was fractionated by size exclusion and RP-HPLC to yield LMW Dsp (AS2R-g).

Chondroitinase activity was detected in the second ion exchange (Q) fraction of the $\mathrm{G} 2$ extact $(\mathrm{G} 2 \mathrm{Q} 2)$.
ANS1/2-R3b into two peptides having apparent molecular weights ranging from 8 - to $25-\mathrm{kDa}$ (Figure 2C). These six peptides were excised and eluted from the gel (Figure 2D) and then characterized by $\mathrm{N}$-terminal sequencing and by amino acid analysis (Figure 2E). The $\mathrm{N}$-terminal sequence and amino acid compositions allowed the complete amino acid sequences of the six peptides to be deduced (Figure 2F).

Peptides 1, 2, 3 and 6 contained the putative GAG attachment site at $\mathrm{Ser}^{238}$ and the amino acid compositions for each of these proteins showed one fewer serine than expected. $\mathrm{N}$-terminal sequence for peptide 3 gave a blank cylce for $\mathrm{Ser}^{238}$. The other $\mathrm{N}$-terminal sequences did not reach $\mathrm{Ser}^{238}$, but the full-length of each peptide could be inferred from its amino acid composition. A blank cycle strongly suggests the presence of a posttranslational modification, but additional evidence is generally required to support this conclusion. In addition, the four peptides containing $\operatorname{Ser}^{238}$ were only 11 or 12 amino acids in length, but migrated at 15-, 17-, 19- and $20-\mathrm{kDa}$ on SDS-PAGE, suggesting they retained variable lengths of GAG attachment following the chondroitinase $\mathrm{ABC}$ digestion. From these data we can safely conclude that $\mathrm{Ser}^{238}$ is a GAG attachment site; however, no information from this experiment was gained on the other putative GAG attachment sites on porcine Dsp (at $\mathrm{Ser}^{220}$ and $\mathrm{Ser}^{250}$ ) [36]. No conclusions could be made from the analyses of peptides 4 and 5. A blank cycle was observed at $\mathrm{Thr}^{200}$, but the amino acid composition suggested that this position was a threonine, and therefore not necessarily modified.

To gain additional information on posttranslational modifications in the GAG attachment region of Dsp, fraction ANS1/2-R3 was digested with pronase. Larger digestion products from the pronase digestion were recovered by size exclusion chromatography in the first eluted fraction (ANS1/2R3-Pr1) (Additional file 3). ANS1/2R3-Pr1 resolved into 26 fractions by RP-HPLC and each was assayed for the presence of glycosylations using the phenol-sulfuric acid assay. Glycosylated peptides were detected in eight of the RP-HPLC fractions: ANS1/2R3Pr1-d, -e, -h through -l, and -p (Additional file 3). To identify peptides with GAG attachments, the eight glycosylated fractions were digested with chondroitinase $A B C$. The peptides were separated from the digested carbohydrate by ethanol precipitation and each supernatant (containing the liberated GAG chains) was analyzed by phenol sulfuric acid assay. Fractions positive for glycan attachments $(-d,-h,-i,-j$, and $-p)$ were rechromatographed using the same $\mathrm{C}-18$ column that was used prior to the chondroitinase $A B C$ digestion. Rechromatographed fractions showing a shift in their retention times relative to same sample prior to chondroitinase $\mathrm{ABC}$ digestion were characterized by 


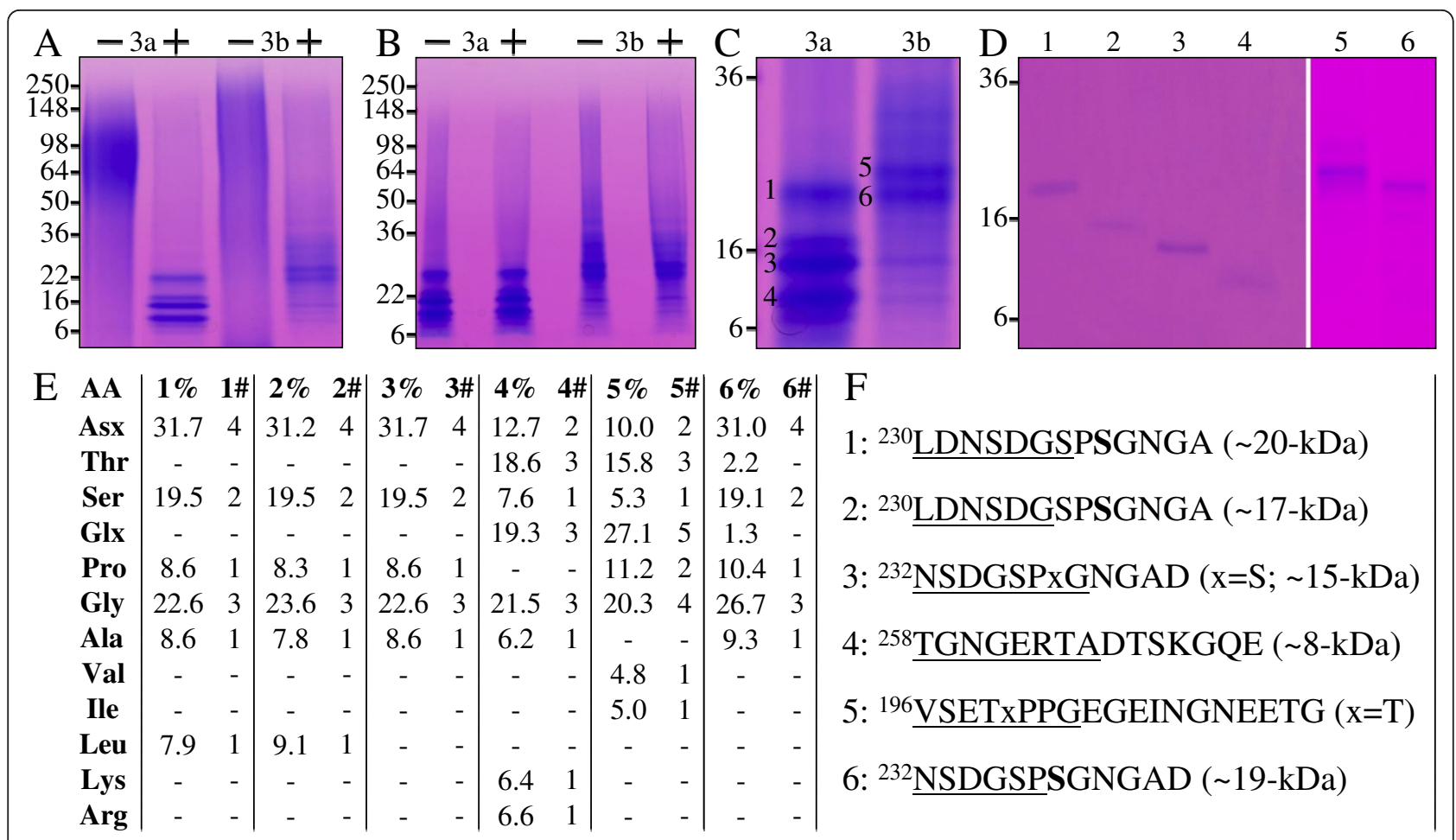

Figure 2 Characterization of small, highly glycosylated Dsp peptides. A: 4-20\% Tris/glycine gel stained with stains-all showing fraction ANS1/2R3-a and -b before (-) and after (+) digestion with chondroitinase ABC. The stains-all positive proteoglycan smears coalesced into a group of protein bands having apparent molecular weights ranging from 8 to $20-\mathrm{kDa}$. B: $4-20 \%$ Tris/glycine gel stained with stains-all showing fraction ANS1/2R3-a and -b without (-) and with (+) the reducing agent $\beta$-mercaptoethanol. The mobilities of the bands did not change indicating the absence of disulfide bridges. C: $4-20 \%$ Tris/glycine gel stained with stains-all showing the bands from ANS1/2R3-a (3a) and ANS1/ 2R3-b (3b) following chondroitinase ABC digestion that were excised from the gel and characterized by amino acid analysis and $\mathrm{N}$-terminal sequencing. $\boldsymbol{D}$ : $18 \%$ Tris/glycine gel stained with stains-all showing the bands following electroelution. $\boldsymbol{E}$ : Results of amino acid analyses showing the percentage (\%) of each amino acid in the 6 peptides and the deduced numbers (\#) of each amino acid. The percentages were converted into number of amino acids by dividing all of the percentages by the lowest meaningful percentage, which corresponded to the percentage of a single amino acid. $\boldsymbol{F}$ : The complete sequences of each peptide. The Edman sequences are underlined with blank cycles indicated by an " $\mathrm{x}$ ".

N-terminal sequencing (Figure 3). One peptide (ANS1/ 2R3Pr1p-P2) gave a blank cycle for Ser ${ }^{238}$, while three peptides (ANS1/2R3Pr1d-D, ANS1/2R3Pr1h-H, and ANS1/2R3Pr1j-J1) gave blank cycles for $\operatorname{Ser}^{250}$. These data demonstrate that $\operatorname{Ser}^{238}$ and $\operatorname{Ser}^{250}$ are the GAG attachment sites for porcine Dsp. The N-terminal sequences of the peptides in fractions ANS1/2R3Pr1-k and ANS1/2R3Pr1-l, which were negative for GAG chains based upon the phenol sulfuric acid assay, were ${ }^{211}$ EETGVxSGGSGA and ${ }^{311}$ TDGDNxSK, respectively. The blank cycles for $\mathrm{Thr}^{216}$ and $\mathrm{Thr}^{316}$ suggest these residues are modified, but these sequences also show that $\operatorname{Ser}^{220}$ and $\mathrm{Asn}^{315}$ (which did not give blank cycles) are not modified, despite their being in appropriate contexts for GAG or N-glycosylation attachments, respectively.

Having established that $\operatorname{Ser}^{238}$ and $\operatorname{Ser}^{250}$, but not $\mathrm{Ser}^{220}$, have GAG attachments, we then characterized the nature of the disaccharide attachments at these two GAG attachment sites. Peptides ANS1/2R3Pr1d-D (with the GAG attached at $\mathrm{Ser}^{250}$ ) and ANS1/2R3Pr1p-P2 (with the GAG attached at $\mathrm{Ser}^{238}$ ) were digested by chondroitinase $\mathrm{ABC}$. The released carbohydrates were obtained from the supernatant following ethanol precipitation of the peptide, and were characterized by their retention times relative to those of disaccharide standards on NP-HPLC (Figure 4). This determined that both GAG attachment sites contained chondroitin-6sulfate (C6S) and chondroitin-4-sulfate (C4S), and integration of the areas under their chromatogram peaks determined that $\mathrm{C} 6 \mathrm{~S}$ and $\mathrm{C} 4 \mathrm{~S}$ are present in a ratio 7 to 3 , respectively.

\section{Characterization of R4 Pronase Digestion Products}

Previously we showed that intact Dsp (Dspp-derived protein that lacks the Dgp and Dpp regions) is in fraction ANS1/2-R4 [42]. This R4 fraction (5 mg) was digested with pronase, and glycosylated peptides were collected in the first peak by size exclusion chromatography (Figure 5A). These peptides resolved into eight 


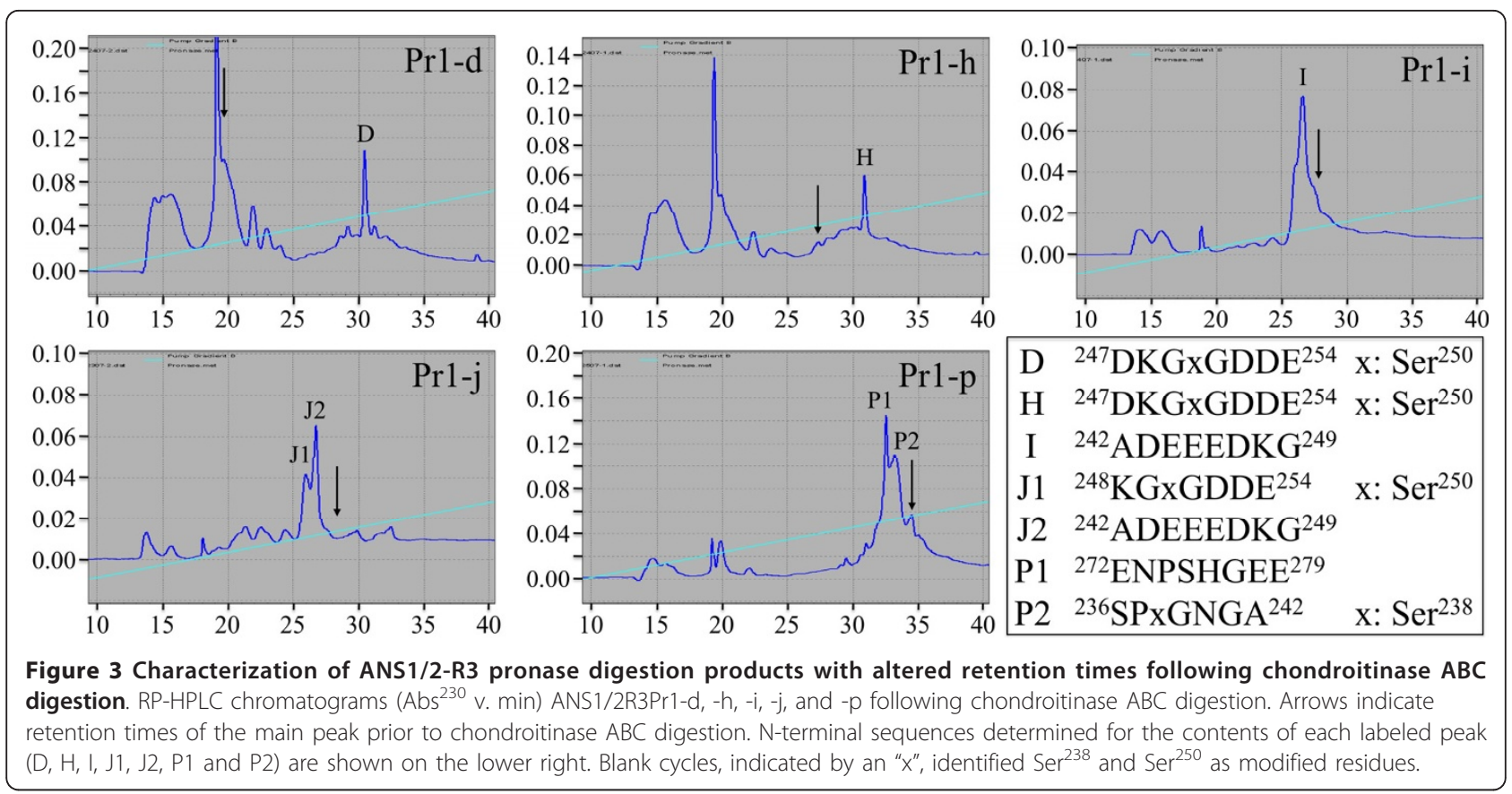

peaks by RP-HPLC (Figure 5B). N-terminal sequencing of these peptides gave blank cycles for $\mathrm{Asn}^{77}, \mathrm{Asn}^{155}$, $\mathrm{Thr}^{200}, \mathrm{Thr}^{216}$, and $\mathrm{Ser}^{250}$.

\section{Characterization of Dsp $\mathrm{N}$-linked glycosylation sites}

Previously we showed by Western blot analyses that low molecular weight (LMW) peptides from the $\mathrm{N}$-terminal region of Dsp can be found in the acid or "A" extract [42]. To identify glycosylated amino acids in these

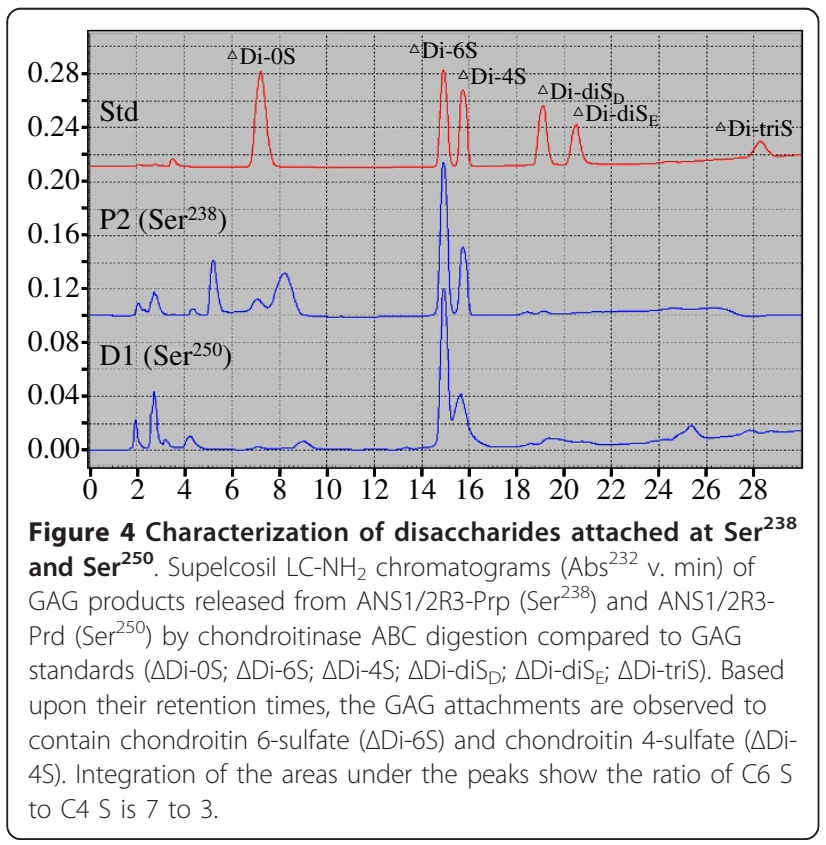

peptides, the A extract was fractionated by size exclusion chromatography followed by RP-HPLC (Additional file 4). The LMW Dsp components in fraction AS2R-g (Figure 6A) were digested with endoproteinase Glu-C (V8 endoproteinase) and the digest was fractionated by RP-HPLC (Figure 6B). Fifteen peaks were observed and each of these fractions was digested with glycopeptidase A. Following the $\mathrm{N}$-deglycosylation, each sample was rechromatographed on the same $\mathrm{C}-18$ column to demonstrate that deglycosylation of the glycopeptide had altered its retention time. A shift in retention time on the column following deglycosylation was accepted as evidence that the original peptide was glycosylated. Fractions corresponding to the main chromatographic peaks that were not present before the glycopeptidase A digestion (AS2R-g peaks 2, 3, 6, 8, 10, 11 and 12) were characterized by LC/MSMS analysis (Figure 6C). Five $\mathrm{N}$-glycosylation sites were identified: $\mathrm{Asn}^{37}$ (NDT; peaks 6, 8, 10, 11, 12), $\operatorname{Asn}^{77}$ (NSS; peaks 6, 8), Asn ${ }^{136}$ (NGS; peaks 2 and 3), $\mathrm{Asn}^{155}$ (NAS; peak 6), $\mathrm{Asn}^{161}$ (NAT; peaks 6, 8), and $\operatorname{Asn}^{176}$ (NNS; peak 2).

\section{Analysis of Sialic Acid in Dsp}

It was known early on that Dsp glycosylations are rich in sialic acid, which was the basis for its designation as dentin sialoprotein [34]. Sialic acid refers to N-acetylneuraminic acid (Neu5Ac) and its derivatives. To determine the amount of $\mathrm{N}$-glycosylations in each Dspp fraction, we released the $\mathrm{N}$-glycosylation with glycopeptidase A and chemically attached a fluorescent label. One fluorescent label was added per N-glycosylation. 


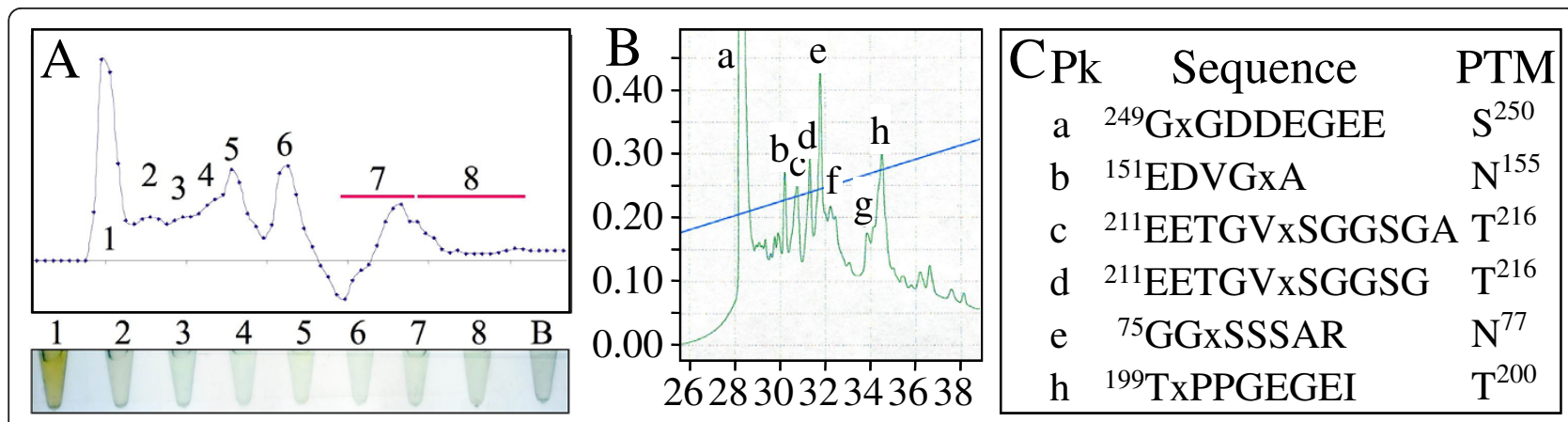

Figure 5 Characterization of glycosylated pronase digestion products of ANS1/2-R4. A: Size exclusion chromatogram (Abs $220 \mathrm{~V}$. min) of ANS1/2-R4 digested with pronase (top); tubes showing results of phenol sulfuric acid assay performed on each size exclusion fraction (bottom; B is "blank" for negative control). B: RP-HPLC chromatogram (Abs ${ }^{220}$ v. min) of digestion products in ANS1/2R4-Pr1 showing the 8 fractions (a-h) collected. C: $\mathrm{N}$-terminal sequences determined for the contents of each fraction peak (Pk). Blank cycles (x) indicate modified residues.

The amount of N-glycosylation in each Dsp fraction was determined by running an aliquot of labeled glycosylation over an SE-HPLC column and then comparing the areas under the chromatographic peaks to that of a commercial A2 glycan standard of known amount and

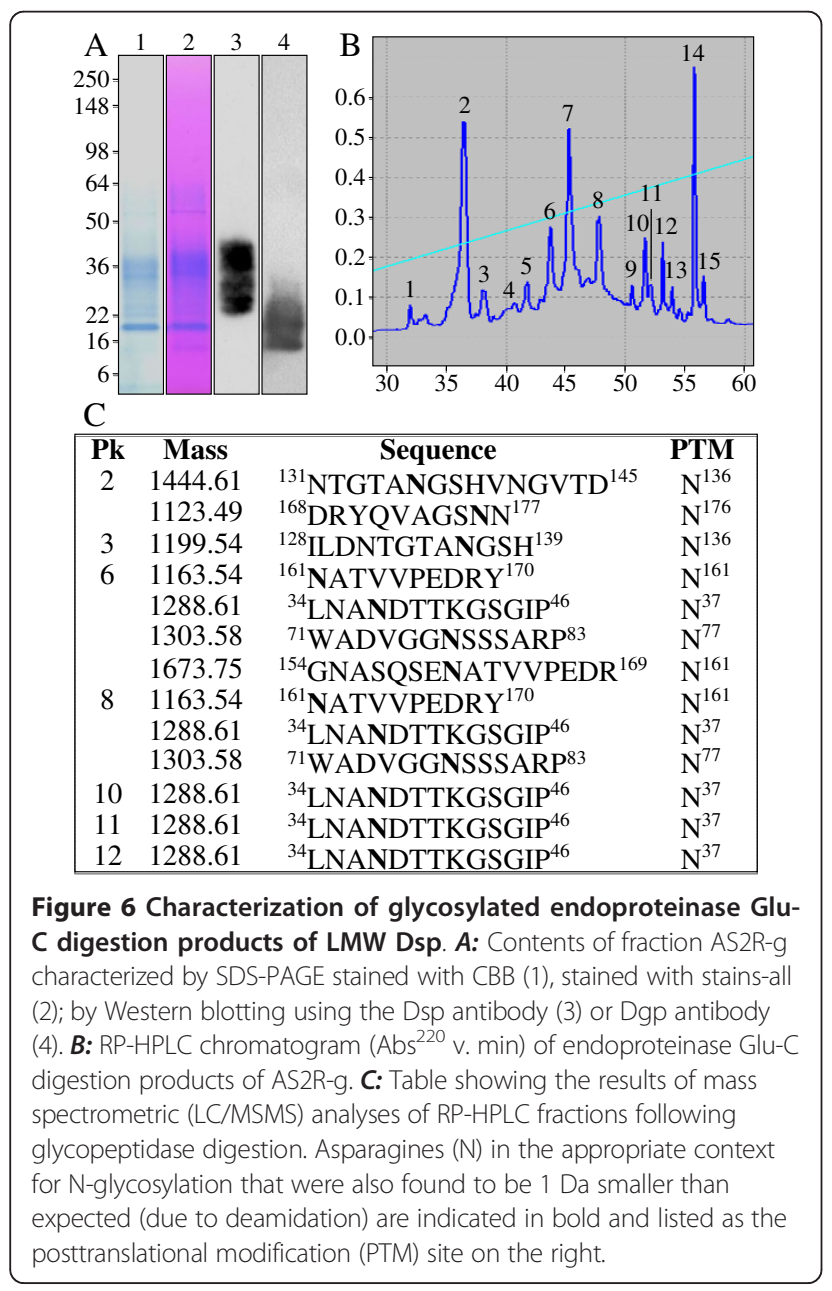

fluorescence (Additional file 5). To quantify the average number of sialic acid attachments per $\mathrm{N}$-glycosylation, we digested LMW-Dsp (containing $\mathrm{N}$-terminal fragments of Dsp) and R5-Dsp (containing Dspp minus the Dpp domain) fractions with sialidase. The released sialic acid was digested with aldolase and the product (pyruvate) and lactic dehydrogenase were used to oxidize $\beta$-NADH to $\beta$-NAD, which was measured spectrophotometrically. The same series of reactions were conducted on a commercial standard (bovine fetuin). The results showed that there were, on average, 1.3 sialic acids per $\mathrm{N}$-glycosylation in the $\mathrm{N}$-terminal region of Dsp, and about 0.8 molecules of sialic acid, on average, per N-glycosylation in Dspp (Additional file 5).

To identify which forms of sialic acid were present on the N-linked glycosylations, $\mathrm{N}$-glycosylations were released from the various Dsp fractions (LMW-Dsp, R3Dsp, R4-Dsp, R5-Dsp), given a fluorescent label, and purified by size exclusion chromatography. Sialic acid was released from these glycosylations by sialidase digestion, labeled, and then passed through a RP-HPLC column. By comparing the retention times of the labeled sialic acid from the Dsp fractions to a similarly-labeled sialic acid reference panel it was demonstrated that all of the sialic acid attached to Dsp N-glycosylations are $\mathrm{N}$-acetylneuraminic acid (Neu5Ac or NANA), which is the predominant form of sialic acid in mammalian cells (Additional file 5).

\section{Discussion}

In this study we identified six $\mathrm{N}$-linked and three tentative O-linked glycosylation and the two GAG attachment sites on porcine Dsp (Figure 7). The two GAG attachment sites are particularly interesting. Xylosyltransferase I (XYLT1; 16p13.1) and xylosyltransferase II (XYLT2; 17q21.3) catalyze the initial step in glycosaminoglycan biosynthesis and determine if a site will have a GAG attachment [49]. Experimentally determined GAG 


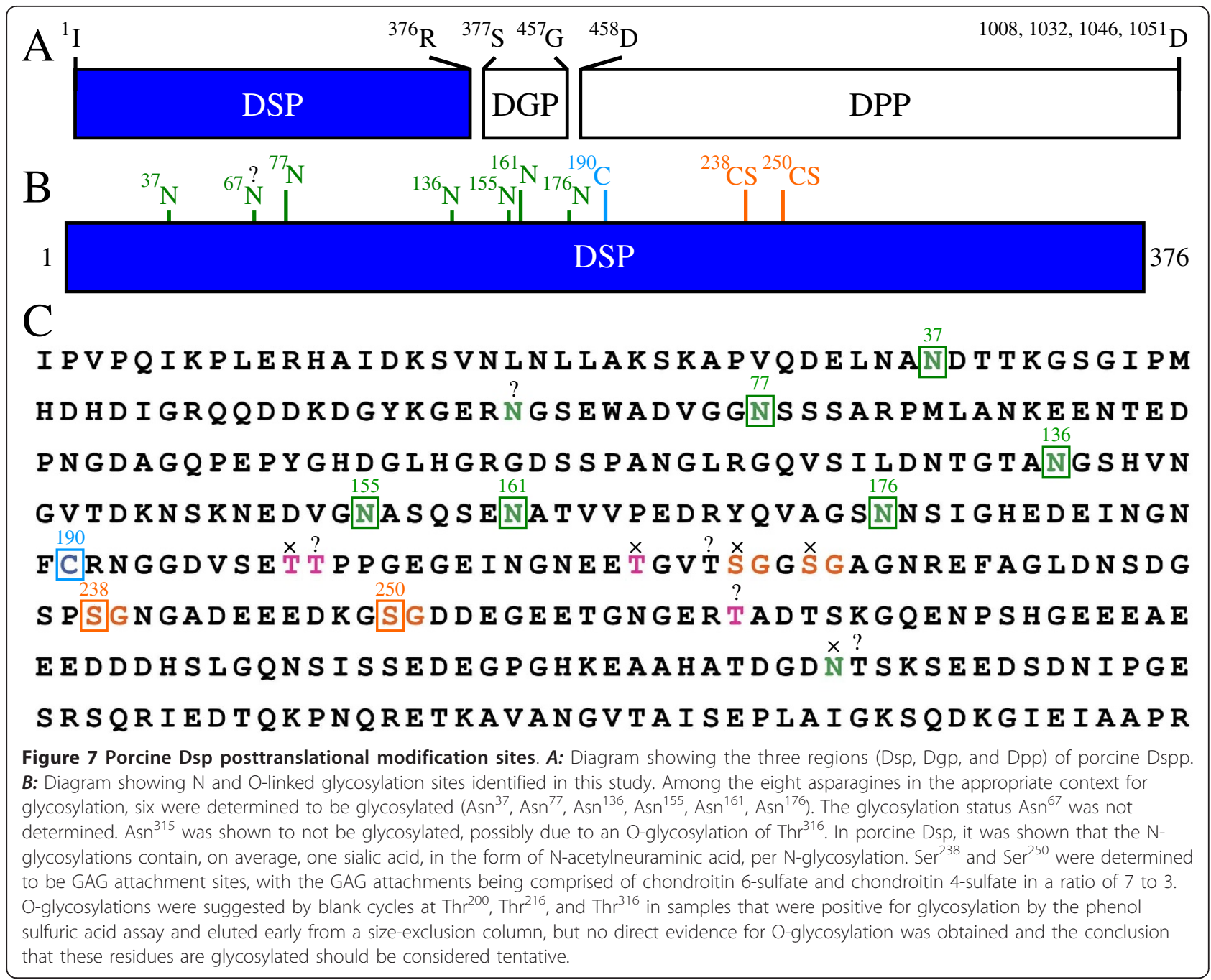

attachment sites identify the range of amino acid contexts that are recognized by these enzymes and provide the data needed to improve the prediction algorythms for GAG attachment sites.

The two GAG attachment sites are in the most highly conserved area of Dsp (Additional file 6). The context for the second site ( $\operatorname{Ser}^{250}$; DEEEDKGSGDDEGEE) contains a GSG-motif combined with a high number of surrounding acidic amino acids, so this sequence would be predicted to be a good acceptor for a xylosylation reaction and result in a high degree of xylosylation catalyzed by both XT-isoforms [50].

The first site ( $\mathrm{Ser}^{238}$, DNSDGSPSGNGADEEED) has two acidic amino acids on the $\mathrm{N}$-terminal side and a series of acidic amino acids starting at positions +5 or +6 , which are positive features. However, the proline in the -1 position is thought to have an inhibitory effect on the glycosylation reaction [51]. Despite this, our results indicate that $\mathrm{Ser}^{238}$ is a GAG attachment site. Perhaps the high conservation of the surrounding amino acids helps ensure its recognition as a target for glycosylation. Recently, it was shown that altering the potential GAG attachment sites sequences in rat Dsp diminished the apparent size of the recombinant protein on Western blots, indicating that both of the GAG attachments sites identified in this study have GAG attachments in rat Dsp [46].

It is clear from our analyses that the repeating disaccharide units attached to $\mathrm{Ser}^{238}$ and $\mathrm{Ser}^{250}$ are chondroitin 6-sulfate and chondroitin 4-sulfate, with C6 S predominating. Based upon antibody analyses, we previously detected only C6 S attached to porcine Dsp [36]. Dentin matrix protein 1 (Dmp1) is a bone and dentin proteoglycan that plays a role in phosphate homeostasis [52]. In rat, the predominant disaccharide unit on Dsp and Dmp1 is C4 S [53,54].

The role of Dsp GAG chains in dentin formation is largely unexplored. Proteoglycans such as decorin are 
known to regulate collagen fibrillogenesis $[55,56]$. GAGs are thought to interact directly with dentin collagen fibrils, as an electrondense substance that can be removed from dentin collagen fibrils by chondroitinase treatment [57]. Dsp is the most abundant proteoglycan in dentin and is therefore likely to interact with collagen. Chondroitinase activity in the dentin matrix might regulate interactions between the Dsp GAG chains and collagen.

Besides having two GAG attachments, porcine Dsp has at least six $\mathrm{N}$-glycosylations. All of these sites are on the $\mathrm{N}$-terminal side of the lone cysteine $\left(\mathrm{Cys}^{190}\right)$ that covalently links two Dsp proteins into a dimer. Although a high degree of $\mathrm{N}$-glycosylation is a characteristic feature of Dsp, the individual glycosylation sites are not well conserved. The N-linked glycosylations on porcine Dsp average about one sialic acid per N-glycosylation. Previously it was shown that rat Dsp contained 29.6\% carbohydrate including about 9\% sialic acid [34]. Sialic acid attachments can serve a wide range of functions [58]. Sialic acid moities can be ligands for other molecules, such as lectins. Perhaps Dsp could form a bridge between molecules that interact with sialic acid and others that interact with O-glycosylations or GAG attachments.

The two O-glycosylations and two GAG attachments are all on the C-terminal side of $\mathrm{Cys}^{190}$. $\mathrm{Ser}^{238}, \mathrm{Ser}^{250}$, and $\mathrm{Thr}^{216}$ are perfectly conserved, whereas $\mathrm{Thr}^{316}$ is conserved in all known Dsp sequences except the mouse. Thus the O-glycosylations and glycosaminoglycan attachments are structural elements that are likely to be essential for Dsp function. Three predicted Golgi casein kinase phosphorylation sites $\left(\mathrm{Ser}^{294}, \mathrm{Ser}^{296}\right.$ and $\mathrm{Ser}^{319}$ ) are all found in the C-terminal side of Dsp and are perfectly conserved.

The map of porcine Dsp posttranslational modifications suggests that Dsp is divided into two domains that are separated by the lone cysteine $\left(\mathrm{Cys}^{190}\right)$ that covalently links two Dsp proteins. The $\mathrm{N}$-terminal side is rich in sialidated $\mathrm{N}$-glycosylations; the $\mathrm{C}$-terminal side contains the GAGs, O-glycosylations, and phosphorylated serines.

The Dsp domain of Dspp is not highly phosphorylated (only 3 predicted sites). In contrast, the small Dgp domain has four perfectly conserved sites, while Dpp has well over a hundred. The Dsp domain is not highly conserved. Only 73 of 377 (19\%) if its amino acids are perfectly conserved among the seven mammalian Dsp sequences in GenBank, whereas 28/81 (35\%) of Dgp is perfectly conserved. The most highly conserved regions of Dsp and Dgp are in areas of posttranslational modifications, highlighting their importance for function. Dsp is important for the onset of dentin mineralization, and future studies will investigate the importance PTMs in carrying out these functions.

\section{Conclusions}

Dentin sialoprotein (Dsp), the N-terminal domain of dentin sialophosphoprotein (Dspp) was isolated from developing porcine molars and its posttranslational modification were characterized. Porcine Dsp has at least $6 \mathrm{~N}$-linked glycosylations ( $\mathrm{Asn}^{37}, \mathrm{Asn}^{77}, \mathrm{Asn}^{136}, \mathrm{Asn}^{155}$, $A s n^{161}$, and $\mathrm{Asn}^{176}$ ) that average one sialic acid each, all in the form of $\mathrm{N}$-acetylneuraminic acid. Porcine Dsp has exactly two glycosaminoglycan attachments $\left(\mathrm{Ser}^{238}\right.$ and $\mathrm{Ser}^{250}$ ) that are comprised of chondroitin 6-sulfate and chondroitin 4-sulfate in a ratio of 7 to 3 . Three O-linked glycosylations in Dsp were tentatively assigned $\left(\mathrm{Thr}^{200}\right.$, $\mathrm{Thr}^{216}$, and $\mathrm{Thr}^{316}$ ). Glycosylations divide porcine Dsp into a heavily $\mathrm{N}$-glycosylated, sialidated $\mathrm{N}$-terminal domain and a C-terminal domain with two GAG attachments, three O-glycosylations, and three potential phosphoserines. The two Dsp domains are separated by the lone cysteine $\left(\mathrm{Cys}^{190}\right)$ that connects two Dsp chains into a covalent dimer. Knowledge of Dsp structure is an important starting point to understanding the how Dsp serves to initiate mineralization of dentin.

\section{Methods}

All experimental procedures involving the use of animals were reviewed and approved by the Institutional Animal Care and Use Program at the University of Michigan.

\section{Extraction of proteins from dentin powder}

Maxillary and mandibular second molar tooth germs were extracted from 6 month old pigs and the soft tissue discarded. Enamel was removed by scraping with a curette and the remaining hard tissue was ground to a powder. All extraction steps were carried out at $4^{\circ} \mathrm{C}$ or on ice. The Protease Inhibitor Cocktail Set III (1 mM AEBSF, 0.8 $\mu \mathrm{M}$ aprotinin, $50 \mu \mathrm{M}$ bestatin, $15 \mu \mathrm{M}$ E-64, $20 \mu \mathrm{M}$ leupeptin, and $10 \mu \mathrm{M}$ pepstatin) (Calbiochem, San Diego, $\mathrm{CA}$ ) and $1 \mathrm{mM}$ 1,10-phenanthroline (Sigma-Aldrich, St. Louis, MO) were added into the buffer during the extraction. The extraction scheme is outlined in Figure 1. Forty grams of dentin powder (the amount obtained from 32 molars) was homogenized at $4^{\circ} \mathrm{C}$ in $50 \mathrm{mM}$ Tris- $\mathrm{HCl} / 4$ $\mathrm{M}$ guanidine buffer ( $\mathrm{pH}$ 7.4) containing protease inhibitors. Insoluble material was pelleted by centrifugation and the supernatant was designated the first guanidine (G1) extract. The guanidine pellet was dialyzed against 4 $\mathrm{L}$ of $0.5 \mathrm{M}$ acetic acid containing protease inhibitors until the tooth mineral has fully dissolved. The dialysis bag contents were centrifuged, and the supernatant was designated the acid (A) extract. The pellet was extracted with $0.5 \mathrm{M}$ acetic acid/2 $\mathrm{M} \mathrm{NaCl}$ and the supernatant was designated the acid salt (AN) extract. The AN pellet was extracted with $50 \mathrm{mM}$ Tris- $\mathrm{HCl} / 2 \mathrm{M} \mathrm{NaCl}$ buffer (pH 7.4) and the supernatant designated the Tris salt 
(TN) extract. The TN pellet was extracted with $50 \mathrm{mM}$ Tris- $\mathrm{HCl} / 4 \mathrm{M}$ guanidine buffer ( $\mathrm{pH}$ 7.4). Residual insoluble material (RIM) was pelleted by centrifugation. The guanidine supernatant was dialyzed against water. Following centrifugation, the pelleted material that had precipitated during dialysis was designated the second guanidine pellet (G2P), while the supernatant was designated the second guanidine extract (G2).

\section{Purification of Dspp-derived proteins}

Western blot analyses using a polyclonal antibody raised against recombinant porcine Dsp [36] showed that low molecular weight (LMW) Dsp components were in the A extract, while high molecular weight (HMW) Dsp components were in the AN extract (Additional file 1). The AN and A extracts were fractionated by size exclusion chromatography and the fraction containing Dsp positive material (based upon Western blot analyses) was further fractionated by reversed phase-high performance liquid chromatography (RP-HPLC). For the AN extract, the HMW Dsp components were found in the first two chromatographic peaks (AN-S1 and AN-S2), which were combined and resolved into five fractions by RP-HPLC [42]. The last three fractions to elute, designated ANS1/2-R3, ANS1/2-R4, and ANS1/2-R5, were comprised of successively larger stains-all positive smears of Dsp proteoglycan, respectively (Additional file $2)$. The LMW Dsp components in the A extract were found in the second (S2) of three fractions produced by size exclusion chromatography. S2 resolved into 14 fractions (designated a through $\mathrm{n}$ ) on a POROS R2 column $(4.6 \mathrm{mmID} \times 10 \mathrm{~cm})$, equilibrated with $0.05 \%$ TFA and eluted with a linear acetonitrile gradient containing $0.05 \%$ TFA at a flow rate of $1.0 \mathrm{~mL} / \mathrm{min}$ at room temperature. The LMW Dsp components were identified in fraction g (AS2R-g; Additional file 4).

To identify glycosylated peptides in porcine Dsp, the LMW and HMW Dsp components were digested with endoproteinase Glu-C or pronase and the glycopeptide products characterized. Endoproteinase Glu-C (Staphylococcus aureus Protease V8) is a serine proteinase that selectively cleaves peptide bonds $\mathrm{C}$-terminal to acidic residues with a strong preference for glutamic over aspartic acid residues [59]. Pronase is a cocktail of proteolytic enzymes that degrades all but short glycopeptides that are protected from cleavage by bulky carbohydrate chains.

\section{Chondroitinase $\mathrm{ABC}$ digestion and characterization ANS1/2-R3}

Fraction ANS1/2-R3, which produced a stains-all positive smear on sodium dodecyl sulfate-polyacrylamide gel electrophoresis (SDS-PAGE), was resolved into two parts (ANS1/S2-R3a and ANS1/S2-R3b) by RP-HPLC rechromatography (Additional file 2), lyophilized, and $200 \mu \mathrm{g}$ of each part was resuspended in $40 \mathrm{mM}$ Tris$\mathrm{HCl} / 40 \mathrm{mM}$ sodium acetate buffer ( $\mathrm{pH} 8.0$ ) and incubated with 0.2 units of chondroitinase $A B C$ protease free (Associate of Cape Cod Inc., East Falmouth, MA) at $37^{\circ} \mathrm{C}$ for $35 \mathrm{~h}$. The digests resolved into six stains-all positive bands on SDS-PAGE, which were excised from the gel. Each gel slice was transferred to a DTube Dialyzer (midi size) (Novagen/EMD Chemicals, Inc., Gibbstown, NJ) and the protein electroeluted with $25 \mathrm{mM}$ Tris/250 mM Tricine/0.025\% SDS buffer ( $\mathrm{pH} \mathrm{8.5)} \mathrm{at} 150$ volts for $3 \mathrm{~h}$. Each eluate was precipitated with $20 \%$ trichloroacetic acid, incubated in acetone overnight at $-80^{\circ} \mathrm{C}$ and centrifuged at $4^{\circ} \mathrm{C}$ for $30 \mathrm{~min}$ at $14,000 \times \mathrm{g}$. The supernatant was decanted, the pellet was dried under a hood, and was later characterized by Edman sequencing.

\section{Characterization of ANS1/2-R3 following pronase digestion}

Purified ANS1/2-R3 (33 mg) in $50 \mathrm{mM}$ Tris- $\mathrm{HCl}$ buffer ( $\mathrm{pH} 8.0$ ) was incubated with $0.2 \mathrm{mg}$ of pronase at $37^{\circ} \mathrm{C}$ for $20 \mathrm{~h}$. The digestion products were fractionated by size exclusion chromatography using a Sephadex G-15 column $(1.6 \mathrm{~cm} \times 60 \mathrm{~cm})$. The first eluted fraction of the pronase digest was positive for oligosaccharide or glycosaminoglycan chains using the phenol-sulphuric acid (PS) assay (Additional file 3) and was fractionated by RP-HPLC using a Discovery C18 column $(10 \mathrm{mmID} \times 25 \mathrm{~cm})$ equilibrated with $0.05 \%$ TFA and eluted with a linear acetonitrile gradient containing $0.05 \%$ TFA at a flow rate of $1.0 \mathrm{~mL} / \mathrm{min}$ at room temperature. For the PS assay, aliquots from each Sephadex G-15 or Discovery C18 fraction were evaporated and $0.3 \mathrm{~mL}$ of water, $0.3 \mathrm{~mL}$ of $5 \%$ phenol, and $1.5 \mathrm{~mL}$ of concentrated sulfuric acid were added. Measuring the absorbance at $490 \mathrm{~nm}$ on a spectrophotometer identified the peak containing oligosaccharides.

Eight RP-HPLC fractions (Pr1-d, -e, -h, -i, -j, -k, -l and -p) that were positive for the PS assay (Additional file 3) were digested with chondroitinase $\mathrm{ABC}$ as described above. At the end of the incubation period, three volumes of ice-cold ethanol were added to the reaction mixture, which was then centrifuged for $10 \mathrm{~min}$ at $10,000 \times \mathrm{g}$. Both supernatant and pellet were lyophilized and stored at $-80^{\circ} \mathrm{C}$. The lyophilized supernatant was dissolved in $0.6 \mathrm{~mL}$ of water and half of the sample was used for the PS assay. The rest of the sample was used for characterization of chondroitin sulfate chains. Two PS negative samples (Pr-1k and l) and five PS positive samples (Pr1$\mathrm{d},-\mathrm{h},-\mathrm{i},-\mathrm{j}$ and $-\mathrm{p}$ ) were rechromatographed by RP-HPLC and characterized by Edman sequencing.

\section{Characterization of LMW Dsp in the A extract}

The AS2R-g (0.5 mg) fraction containing LMW Dsp (Additional file 4) was dissolved with $1 \mathrm{~mL}$ of $0.1 \mathrm{M}$ 
ammonium bicarbonate/1 mM EDTA-2Na buffer ( $\mathrm{pH}$ 7.8). Samples were digested by endoproteinase Glu-C (Roche Diagnostics, Indianapolis, IN) using an enzyme/ substrate ratio of $1 / 25(\mathrm{w} / \mathrm{w})$ at $35^{\circ} \mathrm{C}$ for $24 \mathrm{~h}$. The digests were applied onto a Discovery C-18 $(10 \mathrm{~mm} \times 25 \mathrm{~cm}) \mathrm{col}-$ umn and run at a flow rate of $1.0 \mathrm{~mL} / \mathrm{min}$ and monitored at $220 \mathrm{~nm}$ (Buffer A: 0.05\% TFA; Buffer B: 80\% acetonitrile/buffer A). Fifteen fractions were collected, lyophilized, and rechromatographed over the same column.

The 15 purified Glu-C digestion products (approximately 50-100 $\mu \mathrm{g}$ each) in $0.1 \mathrm{M}$ citrate-phosphate buffer (pH 5.0) were incubated with $0.2 \mathrm{mU}$ of glycopeptidase A (Associate of Cape Cod, East Falmouth, MA, USA) containing the Protease Inhibitor Cocktail Set II $(0.08 \mathrm{mM}$ of AEBSF, $6.8 \mu \mathrm{M}$ of Bestatin, $0.8 \mu \mathrm{M}$ of E-64, $0.35 \mathrm{mM}$ of EDTA and $8 \mu \mathrm{M}$ of Pepstatin A; Calbiochem, San Diego, CA, USA) at $37^{\circ} \mathrm{C}$ for $48 \mathrm{~h}$. Three volumes of ice-cold ethanol were added, then the reaction mixture was centrifuged for $10 \mathrm{~min}$ at 10,000 $\times$ g. Glycopeptides among the Glu-C digestion products were identified by rechromatography using the same Discovery C-18 $(10 \mathrm{~mm} \times 25 \mathrm{~cm})$ column. Seven glycopeptides that showed a shift in their retention times following the glycopeptidase A digestion were characterized by LC/MSMS analysis (Nextgen Sciences, Ann Arbor, MI).

\section{Qualitative and quantitative analyses of sialic acid in Dspp-derived proteins}

$\mathrm{N}$-glycosylations were enzymatically released from purified Dpp (ANS1/2-R2) $(190 \mu \mathrm{g})$, Dsp (ANS1/2R3-R5) (170-250 $\mu \mathrm{g})$, Dgp (AS2Rd-Rf) $(160 \mu \mathrm{g})$, and LMW Dsp (AS2R-g) $(180 \mu \mathrm{g})$ with $1 \mathrm{mU}$ of glycopeptidase A. The porcine $32-\mathrm{kDa}$ enamelin $(90 \mu \mathrm{g})$ was also digested as a positive control. Three volumes of icecold ethanol were added to precipitate the deglycosylated proteins, which were separated from the released $\mathrm{N}$-glycosylations by centrifugation for $10 \mathrm{~min}$ at 10,000 $\times$ g. $\mathrm{N}$-glycosylations in the supernatants were evaporated and labeled with 2 -aminobenzoic acid (2-AA) using 2-AA labeling kit and S Cartridge (QA-bio, Palm Desert, CA). A labeled N-glycan standard (10 pmol; A2 glycan; QA-bio) and the 2-AA-glycosylations were separated by size exclusion-HPLC (SE-HPLC) using a Nanofilm-SEC $150(7.8 \mathrm{~mm} \times 30 \mathrm{~cm})($ Sepax Technologies Inc., Newark, DE) column equilibrated with PBS and was eluted with the same solution at a flow rate of $1.0 \mathrm{~mL} / \mathrm{min}$ at the room temperature. The effluent was continuously monitored by a fluorescence monitor (FP-2020, JASCO, Tokyo, Japan) using an excitation wavelength of $320 \mathrm{~nm}$ and an emission wavelength of $420 \mathrm{~nm}$ (Additional file 5). The amount of released labeled glycosylations was determined by comparing the area under its chromatographic peak with the labeled A2 glycan standard.
For the qualitative analysis of sialic acid, each of the purified 2-AA glycosylation samples in $50 \mathrm{mM}$ sodium phosphate buffer (pH 6.0) was incubated with $10 \mathrm{mU}$ of sialidase $\mathrm{Au}$ (QA-bio) for $1 \mathrm{~h}$ at $37^{\circ} \mathrm{C}$. An aliquot of the released sialic acid was labeled with 1,2-diamino-4,5methylenedioxy-benzene (DMB) using a sialic acid labeling kit (QA-bio). The DMB-sialic acid samples were separated by RP-HPLC using a GlycoSep R $(2.1 \mathrm{~mm} \times$ $15 \mathrm{~cm}$ ) (ProZyme Inc., Hayward, CA) column equilibrated with a mixture of acetonitrile-methanol-water $(9: 7: 84, \mathrm{v} / \mathrm{v})$ and eluted with the same solution at a flow rate of $1.0 \mathrm{~mL} / \mathrm{min}$ at the room temperature. A fluorescence monitor using an excitation wavelength of 373 $\mathrm{nm}$ and an emission wavelength of $448 \mathrm{~nm}$ continuously monitored the effluent. The form of sialic acid in each sample was identified by comparing with retention times of a DMB-labeled sialic acid reference panel (QAbio) (Additional file 5).

For the quantitative analysis of sialic acid we used the SialiQuant sialic acid quantitation kit (QA-bio). LMW Dsp (AS2R-g), HMW Dsp (ANS1/2-R5), and bovine fetuin $(33.6 \mathrm{nmol})$ were digested with sialidase AU. These reactions, as well as $10 \mathrm{nmol}$ of $\mathrm{N}$-acetylneuraminic acid, were digested with $\mathrm{N}$-acetylneuraminic acid aldolase in Tris reaction buffer at $37^{\circ} \mathrm{C}$ for $30 \mathrm{~min}$. A solution of $\beta-\mathrm{NADH}$ was added and the initial $\beta$-NADH absorbance was read at $340 \mathrm{~nm}\left(\mathrm{~A}_{340}\right.$ initial). The reaction mixture was incubated with lactic dehydrogenase for $1 \mathrm{~h}$ at $37^{\circ} \mathrm{C}$, then the final $\beta$-NADH absorbance was read ( $\mathrm{A}_{340}$ final) and the nmoles of sialic acid calculated: nmoles of sialic acid $=\left(\mathrm{A}_{340}\right.$ initial - $\mathrm{A}_{340}$ final $) \times 1000 / 6.22(\mathrm{mM}$ extinction coefficient of $\beta-\mathrm{NADH}$ is 6.22 at $340 \mathrm{~nm}$ ) (Additional file 5). The result for the $10 \mathrm{nmol}$ of $\mathrm{N}$-acetylneuraminic acid was 8.68 nmol, so the results of other samples were corrected by multiplying by 1.15 . For the bovine fetuin control this correction gave a result of $32.42 \mathrm{nmol}$.

\section{SDS-PAGE and Western blotting}

SDS-PAGE was performed using Novex 4-20\% Tris-Glycine Gel (Invitrogen, Carlsbad, CA, USA). Samples were dissolved in Laemmli sample buffer (Bio-Rad) and electrophoresis was carried out using a current of $30 \mathrm{~mA}$ for about $1 \mathrm{~h}$. The gels were stained with Simply Blue Safe Stain (Invitrogen) or Stains-all (Sigma, St. Louis, MO, USA). The apparent molecular weights of protein bands were estimated by comparison with SeeBlue ${ }^{\mathbb{B}}$ Plus2 Pre-Stained Standard (Invitrogen). Proteins were electrotransferred from SDS-PAGE onto a Hybond-ECL nitrocellulose membrane (GE Healthcare Bio-Sciences Corp.). Porcine Dsp and mouse chondroitin 6-sulfate $(\Delta \mathrm{Ch}-6 \mathrm{~S})$ antibodies were used at dilution of 1:50,000. The membrane was immunostained by chemiluminescent detection with ECL Advance Western Blotting Detection Kit (GE Healthcare Bio-Sciences Corp.). 


\section{Amino Acid Analysis}

The purified Dsp samples (ANS1/2-R3 to R5) (20-30 $\mu \mathrm{g})$ were hydrolyzed with $6 \mathrm{~N} \mathrm{HCl}$ at $115^{\circ} \mathrm{C}$ for $16 \mathrm{~h}$. The amino acid analyses were performed using a Hitachi L$8900 \mathrm{PH}$ instrument at the W. M. Keck Biotechnology Resource Lab at Yale University.

\section{Automated Edman Degradation}

Automated Edman degradation used the 494HT ABI Edman Protein Sequencer at the W.M. Keck Biotechnology Resource Lab at Yale University.

\section{Additional material}

\section{Additional file 1: Characterization of porcine dentin powder} extracts by SDS-PAGE and Western blotting. This file shows a CBB and a stains-all SDS-PAGE, and a Western blot using a Dsp polyclonal antibody of porcine dentin power extracts and fractions.

Additional file 2: Purification of high molecular weight (HMW) pieces of Dspp that contained Dsp. This file shows RP-HPLC chromatograms that yielded the ANS1/2-R1 through ANS1/2-R5 fractions and shows these fractions characterized by CBB and stains-all stained SDS-PAGE and Western blotting using a Dsp polyclonal antibody and a Dgp anti-peptide antibody.

Additional file 3: Isolation of glycosylated peptides from the pronase digestion of ANS1/2-R3. This file shows the size exclusion chromatogram of the A extract and characterization of its three major fractions by CBB and stains-all stained SDS-PAGE, and by Western blotting using Dsp polyclonal antibody. It also shows the RP-HPLC chromatogram for separation of the second size exclusion fraction and characterization of the resulting 14 fractions by CBB and stains-all stained SDS-PAGE, and by Western blotting using a Dsp polyclonal antibody.

Additional file 4: Isolation of low molecular weight (LMW) Dsp components in the $\mathbf{A}$ extract. This file shows the size exclusion chromatogram of pronase-digested ANS1/2-R3 reacted with phenolsulfate (to detect glycosylations); the RP-HPLC chromatogram that fractionated the potentially glycosylated pronase digestion products into 26 parts; and the results of a spectrophotometric analysis that identified the 8 fractions containing glycosylated peptides.

\section{Additional file 5: Characterization of sialic acid in Dsp N-}

glycosylations. This file shows the fluorescent chromatograms from size exclusion-HPLC separations of $\mathrm{N}$-glycosylations that were previously released from various Dsp fractions by glycopeptidase A digestion and then labeled with 2-AA to determine the quantity of their labeled glycosylations by comparing the areas of their chromatographic peaks to those generated by known quantities of a 2-AA labeled standard. Fluorescent chromatograms from the RP-HPLC separations of sialic acid released from the $\mathrm{N}$-glycosylations by sialidase digestion and labeled with DMB are shown that, by comparison to sialic acid standards, allowed the determination of the form of sialic acid on Dsp glycosylations ( $\mathrm{N}$-acetylneuraminic acid).

Additional file 6: Alignment of Dsp amino acid sequences from GenBank. This file shows the amino acid alignment of Dsp from pig, panda, dog, monkey, human, mouse and rat, highlighting the conservation of modified sequences.

\section{List of Abbreviations Used}

A: Acid extract; AN: acid-salt extract; Bmp: bone morphogenetic protein; A2 glycan: disialo-galactosylated biantennary oligosaccharide; $\triangle \mathrm{Di}-\mathrm{OS}$ : 2acetamido-2-deoxy-3-O-(beta-D-gluco-4-enepyranosyluronic acid)-Dgalactose; $\triangle \mathrm{Di}$-4S: 2-acetamido-2-deoxy-3-O-(beta-D-gluco-4enepyranosyluronic acid)-4-O-sulfo-D-galactose; $\triangle \mathrm{Di}$-6S: 2-acetamido-2-
deoxy-3-O-(beta-D-gluco-4-enepyranosyluronic acid)-6-O-sulfo-D-galactose; $\triangle \mathrm{Di}$-diS : 2-acetamide-2-deoxy-3-O-(2-O-sulfo-b-D-gluco-4enepyranosyluronic acid)-6-O-sulfo-D-galactose; $\triangle \mathrm{Di}$-diS $\mathrm{E}_{\mathrm{E}}$ : 2-acetamide-2deoxy-3-O-(b-D-gluco-4-enepyranosyluronic acid)-4,6-bis-O-sulfo-D-galactose; $\triangle$ Di-triS: 2-acetamido-2-deoxy-3-O-(2-O-sulfo-b-d-gluco-4-enepyranosyluronic acid)-4,6-di-O-sulfo-d-galactose; DD: dentin dysplasia; DGI: dentinogenesis imperfecta; Dgp: dentin glycoprotein; DMB: 1,2-diamino-4,5-

methyleneoxybenzene; Dmp1: dentin matrix protein 1; Dsp: dentin sialoprotein; Dspp: dentin sialophosphoprotein; G1: first guanidine extract; G2P: second guanidine pellet; G2: second guanidine extract. GAG: glycosaminoglycan; LMW: low molecular weight; HMW: high molecular weight; HPLC: high performance liquid chromatography; Mmp: matrix metalloproteinase; $\beta$-NADH: beta-nicotinamide adenine dinucleotide. NPHPLC: normal phase-high performance liquid chromatography; Pr: pronase size exclusion fraction; PS: phenol-sulphuric acid; RIM: Residual insoluble material; R: RP-HPLC fraction; RP-HPLC: reversed phase-high performance liquid chromatography; S: size exclusion fraction; SDS-PAGE: sodium dodecyl sulfate-polyacrylamide gel electrophoresis; SCPP: secretory calcium-binding phosphoprotein; SE-HPLC: size exclusion-high performance liquid chromatography; SIBLINGs: small integrin-binding ligand, N-linked glycoproteins; TN: tris-salt extract; 2-AA: 2-aminobenzoic acid.

\section{Acknowledgements}

We thank Dr. Doris Hendig of the Institute of Laboratory and Transfusion Medicine of the Heart and Diabetes Center in Bad Oeynhausen, Germany for her expert opinion regarding putative GAG attachment sites; Tom Forton, manager of the Michigan State University Meat Laboratory and members of the Michigan State University Department of Animal Science for their kind assistance in obtaining fresh developing molars from pigs; Nancy Williams, Fernando Pineda and Myron Crawford, for protein sequencing and amino acid analysis at the W.M. Keck Foundation Biotechnology Resource Laboratory at Yale University; and Dave Allen, Lead Project Manager at NextGen Sciences, Inc for the mass spectrometry analyses. This work was supported by the National Institute of Dental and Craniofacial Research (NIDCR), of the U.S. National Institutes of Health, grant DE018020

\section{Author details}

'Department of Biologic and Materials Sciences, University of Michigan School of Dentistry, 1210 Eisenhower Place, Ann Arbor, Ml, 48108, USA. ${ }^{2}$ Department of Periodontics and Endodontics, School of Dental Medicine, Tsurumi University, 2-1-3 Tsurumi, Tsurumi-ku, Yokohama 230-8501, Japan.

\section{Authors' contributions}

All authors (YY, TN, JH, FY and JPS) made substantive intellectual contributions to the study, were involved in drafting and revising the manuscript, and have given final approval of the version to be published.

Received: 30 July 2010 Accepted: 3 February 2011

Published: 3 February 2011

\section{References}

1. Linde A, Lussi A, Crenshaw MA: Mineral induction by immobilized polyanionic proteins. Calcif Tissue Int 1989, 44(4):286-295.

2. Veis A, Perry A: The phosphoprotein of the dentin matrix. Biochemistry 1967, 6(8):2409-2416.

3. Leaver AG, Triffitt JT, Holbrook IB: Newer knowledge of non-collagenous protein in dentin and cortical bone matrix. Clin Orthop Relat Res 1975, 110:269-292.

4. Dimuzio MT, Veis A: Phosphophoryns-major noncollagenous proteins of rat incisor dentin. Calcif Tissue Res 1978, 25(2):169-178.

5. Linde A, Bhown M, Butler WT: Noncollagenous proteins of dentin. A reexamination of proteins from rat incisor dentin utilizing techniques to avoid artifacts. J Biol Chem 1980, 255(12):5931-5942.

6. Shields ED, Bixler D, el-Kafrawy AM: A proposed classification for heritable human dentine defects with a description of a new entity. Arch Oral Biol 1973, 18(4):543-553.

7. O'Connell AC, Marini JC: Evaluation of oral problems in an osteogenesis imperfecta population. Oral Surg Oral Med Oral Path Oral Radiol Endod 1999, 87(2):189-196. 
8. Zhang X, Zhao J, Li C, Gao S, Qiu C, Liu P, Wu G, Qiang B, Lo WH, Shen Y DSPP mutation in dentinogenesis imperfecta Shields type II. Nat Genet 2001, 27(2):151-152.

9. Xiao S, Yu C, Chou X, Yuan W, Wang Y, Bu L, Fu G, Qian M, Yang J, Shi Y, et al: Dentinogenesis imperfecta 1 with or without progressive hearing loss is associated with distinct mutations in DSPP. Nat Genet 2001, 27(2):201-204.

10. Rajpar MH, Koch MJ, Davies RM, Mellody KT, Kielty CM, Dixon MJ: Mutation of the signal peptide region of the bicistronic gene DSPP affects translocation to the endoplasmic reticulum and results in defective dentine biomineralization. Hum Mol Genet 2002, 11(21):2559-2565.

11. Malmgren B, Lindskog S, Elgadi A, Norgren S: Clinical, histopathologic, and genetic investigation in two large families with dentinogenesis imperfecta type II. Hum Genet 2004, 114(5):491-498.

12. Kim JW, Nam SH, Jang KT, Lee SH, Kim CC, Hahn SH, Hu JC, Simmer JP: A novel splice acceptor mutation in the DSPP gene causing dentinogenesis imperfecta type II. Hum Genet 2004, 115(3):248-254.

13. Kim JW, Hu JC, Lee Jl, Moon SK, Kim YJ, Jang KT, Lee SH, Kim CC, Hahn SH, Simmer JP: Mutational hot spot in the DSPP gene causing dentinogenesis imperfecta type II. Hum Genet 2005, 116(3):186-191.

14. Holappa H, Nieminen P, Tolva L, Lukinmaa PL, Alaluusua S: Splicing site mutations in dentin sialophosphoprotein causing dentinogenesis imperfecta type II. Eur J Oral Sci 2006, 114(5):381-384.

15. Zhang X, Chen L, Liu J, Zhao Z, Qu E, Wang X, Chang W, Xu C, Wang QK Liu M: A novel DSPP mutation is associated with type II dentinogenesis imperfecta in a Chinese family. BMC Med Genet 2007, 8:52

16. Hart PS, Hart TC: Disorders of human dentin. Cells Tissues Organs 2007, 186(1):70-77.

17. Wang H, Hou Y, Cui Y, Huang Y, Shi Y, Xia X, Lu H, Wang Y, Li X: A novel splice site mutation in the dentin sialophosphoprotein gene in a Chinese family with dentinogenesis imperfecta type II. Mutat Res 2008, 6:6.

18. Lee SK, Hu JC, Lee KE, Simmer JP, Kim JW: A dentin sialophosphoprotein mutation that partially disrupts a splice acceptor site causes type II dentin dysplasia. J Endod 2008, 34(12):1470-1473.

19. McKnight DA, Simmer JP, Hart PS, Hart TC, Fisher LW: Overlapping DSPP mutations cause dentin dysplasia and dentinogenesis imperfecta. J Dent Res 2008, 87(12):1108-1111.

20. McKnight DA, Suzanne Hart P, Hart TC, Hartsfield JK, Wilson A, Wright JT, Fisher LW: A comprehensive analysis of normal variation and diseasecausing mutations in the human DSPP gene. Hum Mutat 2008, 29(12):1392-1404.

21. Song YL, Wang CN, Fan MW, Su B, Bian Z: Dentin phosphoprotein frameshift mutations in hereditary dentin disorders and their variation patterns in normal human population. J Med Genet 2008, 45(7):457-464.

22. Kida M, Tsutsumi T, Shindoh M, Ikeda $H$, Ariga T: De novo mutation in the DSPP gene associated with dentinogenesis imperfecta type II in a Japanese family. Eur J Oral Sci 2009, 117(6):691-694

23. Lee $S K$, Lee KE, Jeon D, Lee $G$, Lee $H$, Shin CU, Jung YJ, Lee $S H$, Hahn $S H$ Kim JW: A novel mutation in the DSPP gene associated with dentinogenesis imperfecta type II. J Dent Res 2009, 88(1):51-55.

24. Bai H, Agula H, Wu Q, Zhou W, Sun Y, Qi Y, Latu S, Chen Y, Mutu J, Qiu C: A novel DSPP mutation causes dentinogenesis imperfecta type II in a large Mongolian family. Bmc 11:23.

25. Kim JW, Simmer JP: Hereditary dentin defects. J Dent Res 2007 86(5):392-399

26. MacDougall M, Simmons D, Luan X, Nydegger J, Feng J, Gu TT: Dentin phosphoprotein and dentin sialoprotein are cleavage products expressed from a single transcript coded by a gene on human chromosome 4. Dentin phosphoprotein DNA sequence determination. J Biol Chem 1997, 272(2):835-842.

27. Begue-Kirn C, Krebsbach PH, Bartlett JD, Butler WT: Dentin sialoprotein, dentin phosphoprotein, enamelysin and ameloblastin: tooth-specific molecules that are distinctively expressed during murine dental differentiation. Eur J Oral Sci 1998, 106(5):963-970

28. Qin C, Brunn JC, Cadena E, Ridall A, Tsujigiwa H, Nagatsuka H, Nagai N, Butler WT: The expression of dentin sialophosphoprotein gene in bone. J Dent Res 2002, 81(6):392-394.

29. Kawasaki K: The SCPP gene repertoire in bony vertebrates and graded differences in mineralized tissues. Dev Genes Evol 2009, 3:147-157.
30. Kawasaki K, Suzuki T, Weiss KM: Genetic basis for the evolution of vertebrate mineralized tissue. Proc Natl Acad Sci USA 2004, 101(31):11356-11361.

31. Brunati AM, Marin O, Bisinella A, Salviati A, Pinna LA: Novel consensus sequence for the Golgi apparatus casein kinase, revealed using prolinerich protein-1 (PRP1)-derived peptide substrates. Biochem J 2000, 351(Pt 3):765-768

32. Fisher LW, Torchia DA, Fohr B, Young MF, Fedarko NS: Flexible structures of SIBLING proteins, bone sialoprotein, and osteopontin. Biochem Biophys Res Commun 2001, 280(2):460-465.

33. Kawasaki K, Buchanan AV, Weiss KM: Biomineralization in humans: making the hard choices in life. Annu Rev Genet 2009, 43:119-142.

34. Ritchie $H H$, Hou H, Veis A, Butler WT: Cloning and sequence determination of rat dentin sialoprotein, a novel dentin protein. $J$ Biol Chem 1994, 269(5):3698-3702

35. Yamakoshi Y, Hu JC, Liu S, Zhang C, Oida S, Fukae M, Simmer JP: Characterization of porcine dentin sialoprotein (DSP) and dentin sialophosphoprotein (DSPP) cDNA clones. Eur J Oral Sci 2003, 111(1):60-67.

36. Yamakoshi Y, Hu JC, Fukae M, Iwata T, Kim JW, Zhang H, Simmer JP Porcine dentin sialoprotein is a proteoglycan with glycosaminoglycan chains containing chondroitin 6-sulfate. J Biol Chem 2005, 280(2):1552-1560.

37. Yamakoshi Y, Hu JC, Fukae M, Zhang H, Simmer JP: Dentin glycoprotein: the protein in the middle of the dentin sialophosphoprotein chimera. J Biol Chem 2005, 280(17):17472-17479.

38. Yamakoshi Y, Lu Y, Hu JC, Kim JW, Iwata T, Kobayashi K, Nagano T, Yamakoshi F, Hu Y, Fukae M, et al: Porcine dentin sialophosphoprotein Length polymorphisms, glycosylation, phosphorylation, and stability. J Biol Chem 2008, 283(21):14835-14844.

39. von Marschall Z, Fisher LW: Dentin sialophosphoprotein (DSPP) is cleaved into its two natural dentin matrix products by three isoforms of bone morphogenetic protein-1 (BMP1). Matrix Biol 2010, 29(4):295-303.

40. Sun Y, Lu Y, Chen S, Prasad M, Wang X, Zhu Q, Zhang J, Ball H, Feng J, Butler WT, et al: Key proteolytic cleavage site and full-length form of DSPP. J Dent Res 2010, 89(5):498-503.

41. Tsuchiya S, Simmer JP, Hu JC-C, Richardson AS, F Y, Yamakoshi Y: Astacin Proteases Cleave Dentin Sialophosphoprotein (Dspp) to Generate Dentin Phosphoprotein (Dpp). J Bone Miner Res 2011, 26(1):220-228.

42. Yamakoshi Y, Hu JC, Iwata T, Kobayashi K, Fukae M, Simmer JP: Dentin sialophosphoprotein is processed by MMP-2 and MMP-20 in vitro and in vivo. J Biol Chem 2006, 281(50):38235-38243.

43. Gu K, Chang S, Ritchie HH, Clarkson BH, Rutherford RB: Molecular cloning of a human dentin sialophosphoprotein gene. Eur J Oral Sci 2000 108(1):35-42

44. Patel P: Soundbites. Nat Genet 2001, 27(2):129-130

45. Qin C, Baba O, Butler WT: Post-translational modifications of sibling proteins and their roles in osteogenesis and dentinogenesis. Crit Rev Oral Biol Med 2004, 15(3):126-136

46. Zhu Q, Sun Y, Prasad M, Wang X, Yamoah AK, Li Y, Feng J, Qin C: Glycosaminoglycan Chain of Dentin Sialoprotein Proteoglycan. J Dent Res 2010, 16.

47. Sreenath T, Thyagarajan T, Hall B, Longenecker G, D'Souza R, Hong S, Wright JT, MacDougall M, Sauk J, Kulkarni AB: Dentin sialophosphoprotein knockout mouse teeth display widened predentin zone and develop defective dentin mineralization similar to human dentinogenesis imperfecta type III. J Biol Chem 2003, 278(27):24874-24880.

48. Suzuki S, Sreenath T, Haruyama N, Honeycutt C, Terse A, Cho A, Kohler T, Muller R, Goldberg M, Kulkarni AB: Dentin sialoprotein and dentin phosphoprotein have distinct roles in dentin mineralization. Matrix Biol 2009, 28(4):221-229.

49. Gotting C, Kuhn J, Kleesiek K: Human xylosyltransferases in health and disease. Cell Mol Life Sci 2007, 64(12):1498-1517.

50. Roch C, Kuhn J, Kleesiek K, Gotting C: Differences in gene expression of human xylosyltransferases and determination of acceptor specificities for various proteoglycans. Biochem Biophys Res Commun 2010, 391(1):685-691.

51. Wang H, Julenius K, Hryhorenko J, Hagen FK: Systematic Analysis of proteoglycan modification sites in Caenorhabditis elegans by scanning mutagenesis. J Biol Chem 2007, 282(19):14586-14597. 
52. Feng JQ, Ward LM, Liu S, Lu Y, Xie Y, Yuan B, Yu X, Rauch F, Davis SI, Zhang S, et al: Loss of DMP1 causes rickets and osteomalacia and identifies a role for osteocytes in mineral metabolism. Nat Genet 2006, 38(11):1310-1315.

53. Qin C, Huang B, Wygant JN, Mclntyre BW, McDonald CH, Cook RG, Butler WT: A chondroitin sulfate chain attached to the bone dentin matrix protein $1 \mathrm{NH} 2$-terminal fragment. J Biol Chem 2006, 281(12):8034-8040.

54. Huang B, Sun Y, Maciejewska I, Qin D, Peng T, Mclntyre B, Wygant J, Butler WT, Qin C: Distribution of SIBLING proteins in the organic and inorganic phases of rat dentin and bone. Eur J Oral Sci 2008, 116(2):104-112.

55. Danielson KG, Baribault H, Holmes DF, Graham H, Kadler KE, lozzo RV: Targeted disruption of decorin leads to abnormal collagen fibril morphology and skin fragility. J Cell Biol 1997, 136(3):729-743.

56. Iozzo RV: Matrix proteoglycans: from molecular design to cellular function. Annu Rev Biochem 1998, 67:609-652.

57. Dechichi P, Biffi JC, Moura CC, de Ameida AW: A model of the early mineralization process of mantle dentin. Micron 2007, 38(5):486-491.

58. Schauer R: Sialic acids as regulators of molecular and cellular interactions. Curr Opin Struct Biol 2009, 19(5):507-514.

59. Breddam K, Meldal M: Substrate preferences of glutamic-acid-specific endopeptidases assessed by synthetic peptide substrates based on intramolecular fluorescence quenching. Eur J Biochem 1992, 206(1):103-107.

doi:10.1186/1471-2091-12-6

Cite this article as: Yamakoshi et al.: Porcine dentin sialoprotein glycosylation and glycosaminoglycan attachments. BMC Biochemistry 2011 12:6.

\section{Submit your next manuscript to BioMed Central} and take full advantage of:

- Convenient online submission

- Thorough peer review

- No space constraints or color figure charges

- Immediate publication on acceptance

- Inclusion in PubMed, CAS, Scopus and Google Scholar

- Research which is freely available for redistribution

Submit your manuscript at www.biomedcentral.com/submit 